\title{
AVALIAÇÃO DO MÉTODO DE LEVANTAMENTO MORFOMÉTRICO EM BACIAS HIDROGRÁFICAS ATRAVÉS DA ESTATÍSTICA MULTIVARIADA
}

\author{
Marcia Regina Gomes de Jesus Soares ${ }^{1}$ \\ Chisato Oka-Fiori ${ }^{2}$ \\ Claudinei Taborda da Silveira ${ }^{3}$ \\ Eloy Kaviski ${ }^{4}$
}

\begin{abstract}
Resumo: A presente pesquisa teve como objetivo principal validar o método de levantamento morfométrico em bacias hidrográficas através da estatística multivariada. Para isso foram consideradas variáveis fisiográficas que foram confrontadas com os dados de vazão com o objetivo de conhecer as variáveis principais e determinantes no comportamento hidrológico. O estudo foi aplicado em todo o complexo hidrográfico do Ivaí, subdividido em 14 sub-bacias, de acordo com as estações de coletas de vazões e com características hidrológicas distintas a fim de comparação. Os indicadores fisiográficos foram confrontados com os dados hidrológicos de vazão e pluviosidade com séries históricas de um período de vinte e sete anos. O resultado conclusivo foi a confirmação da eficiência do modelo de análise.
\end{abstract}

Palavras-chave: Modelo de análise; Variáveis fisiográficas; Gestão integrada

\section{EVALUATION OF THE MORPHOMETRIC LIFTING METHOD IN HYDROGRAPHIC BASIN THROUGH MULTIVARIATE STATISTICS}

\begin{abstract}
This research aimed to validate the method of morphometric survey in watersheds with multivariate statistical. For this were taken into account physiographic variables they were confronted with the data flow in order to meet the main and determinants variables in hydrology. The study was applied throughout the complex hydrographic Ivaí, subdivided into 14 sub-basins, according to streamflow collection stations, with distinct hydrological characteristics order to compare. Physiographic indicators were faced with hydrological flow data and rainfall time series with a period of twenty-seven years. Through the integration of the information was obtained as conclusive result to confirm the efficiency of the analysis model.
\end{abstract}

Keywords: Analysis model; Physiographic variables; Integrated management

\section{EVALUACIÓN DEL MÉTODO DE LEVANTAMIENTO MORFOMÉTRICO EN CUENCAS HIDROGRÁFICAS A TRAVÉS DE LA ESTADÍSTICA MULTIVARIADA}

\footnotetext{
${ }^{1}$ Doutora em Geografia (UFPR). Professora contratada pela Secretaria Estadual de Educação do Paraná, Email: marcia.rgsoares@gmail.com

2 Doutora em Geografia; Professora Senior, do Departamento de Geografia, do Setor de Ciências da Terra da Universidade Federal do Paraná. Email: piofiori@terra.com.br

${ }^{3}$ Professor Departamento de Geografia da Universidade Federal do Paraná. Email: claudinei.ufpr@ yahoo.com.br

${ }^{4}$ Universidade Federal do Paraná. Email: eloy.dhs@ufpr.br
} 
Resumen: La presente investigación tuvo como objetivo principal validar el método de levantamiento morfométrico en cuencas hidrográficas a través de la estadística multivariada. Para ello se consideraron variables fisiográficas que se enfrentaron con los datos de flujo con el objetivo de conocer las variables principales y determinantes en el comportamiento hidrológico. El estudio fue aplicado en todo el complejo hidrográfico del Ivaí, subdividido en 14 subcuencas, de acuerdo con las estaciones de colectas de caudales y con características hidrológicas distintas a fin de comparación. Los indicadores fisiográficos se enfrenta a los datos hidrológicos de flujo y pluviosidad con series históricas de un período de veintisiete años. El resultado conclusivo fue la confirmación de la eficiencia del modelo de análisis.

Palabras clave: Modelo de análisis; Variables fisiográficas; Gestión integrada

\section{INTRODUÇÃO}

A análise morfométrica em bacias hidrográficas, através das características geomorfológicas associadas ao relevo e à rede de drenagem, possibilita a identificação de suas características gerais. Estas medidas podem servir como um referencial para o planejamento ambiental e proposta de reestruturação regional, com o intuito de auxiliar a tomada de decisão de projetos envolvendo o uso de recursos físicos na região (SOARES; SOUZA, 2012).

A combinação dos diversos dados morfométricos permite a diferenciação de áreas homogêneas (ANTONELLI; THOMAZ, 2007). Estes parâmetros podem revelar indicadores físicos específicos para um determinado local, de forma a qualificarem as alterações ambientais. Destaca-se também sua importância nos estudos sobre vulnerabilidade ambiental em bacias hidrográficas.

No entanto, tendo em vista a quantidade de metodologias existentes na literatura que objetiva a análise do meio físico, nota-se a carência de inserção de variáveis significativas, como as hidrológicas, e isto ocorre no método de levantamento morfométrico de canais fluviais. Partindo deste pressuposto, a motivação para o desenvolvimento desta pesquisa baseia-se na intenção em contemplar variáveis de vazão para a análise e gestão de elementos físicos da paisagem e seus processos, o que é extremamente necessário para se chegar a resultados significativos. Também da preocupação de verificar se métodos que se fundamentam na atribuição de resultados numéricos para se chegar a generalizações sobre áreas estudadas são coerentes com a realidade.

Com o exposto, a presente pesquisa teve como objetivo geral validar, com dados hidrológicos de vazão, o método de levantamento morfométrico em bacias hidrográficas, na escala regional, através da análise estatística multivariada. 


\section{ÁREA DE ESTUDO}

A área de estudo da presente pesquisa, designada bacia hidrográfica do Ivaí (Figura 1), foi selecionada por apresentar dados de vazão e chuva adequados aos objetivos propostos, além de mapas regionais na escala 1:250.000, afim de verificação se os métodos analisados mostram compatibilidades com esta escala, com as imagens no formato raster e com os dados hidrológicos. A bacia hidrográfica do Ivaí, inteiramente inserida no território paranaense, nas regiões que compreende o segundo e o terceiro planalto, localiza-se entre as coordenadas UTM 224.214,2 $\mathrm{m}$ e 7.465.630,6 m; 525.920,2 m e 7.170.625,7 m, apresentando uma área total de $35.845 \mathrm{~km}^{2}$.

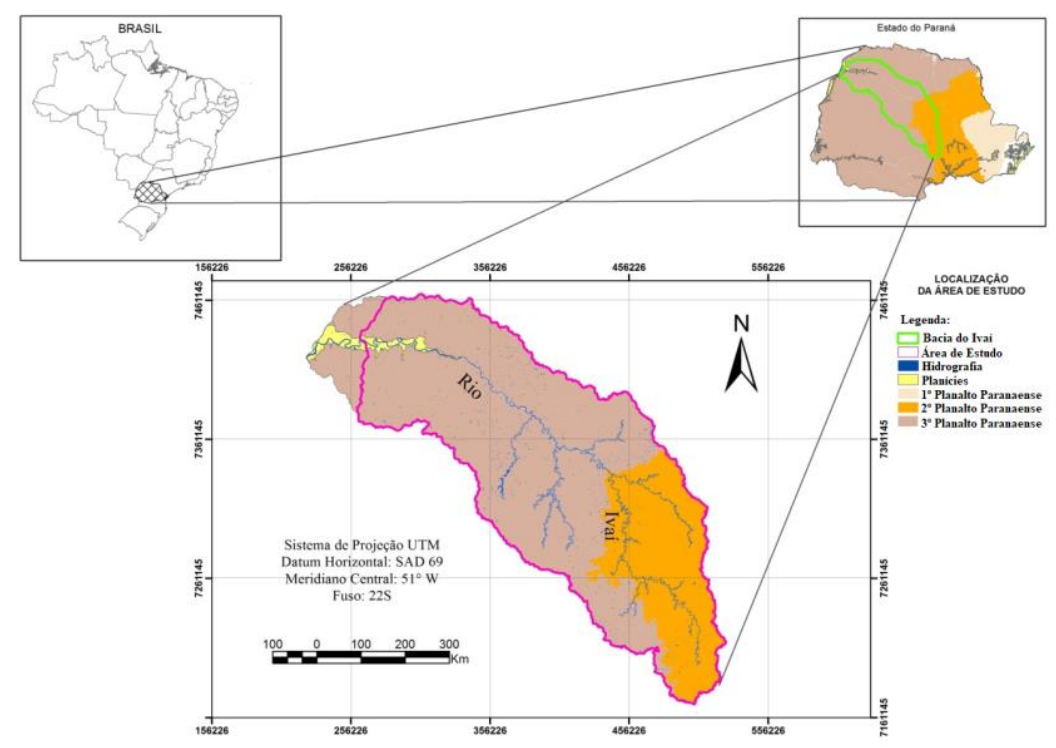

Figura 1: Localização da área de estudo: Bacia do rio Ivaí PR.

O rio Ivaí surge da confluência dos rios Dos Patos e São João, na Porção Sul do Estado do Paraná, precisamente na região denominada Serra da Boa Esperança, na divisa dos municípios de Prudentópolis e Ivaí (BALDO, 2006).

Os dados geológicos são compostos de sedimentos correspondentes ao grupo Passa Dois, compreendendo as formações Irati, Serra Alta, Terezina e Rio do Rasto; Grupo São Bento, que abrange as formações Piramboia e Botucatu; Formação Serra Geral, que recobriu grande parte do imenso deserto de Botucatu; o arenito da Formação Caiuá do grupo Bauru; e, em alguns locais, parcialmente recobertas por sedimentos inconsolidados. (BALDO, 2006).

Segundo Maack (1981), o sistema orográfico da bacia do rio Ivaí evidencia claramente a correlação das formas existentes com a constituição geológica. As altitudes na bacia 
variam de menos 300 a mais de 1.300 metros desde a foz até a nascente. O rio Ivaí nasce no Segundo Planalto e corta todo o Terceiro Planalto em sentido noroeste.

Essa bacia por apresentar grande extensão territorial possui também uma variedade muito grande de solos. Dentre os mais encontrados, destacam-se: Cambissolos, Latossolos, Argissolos, Nitossolos e os Neossolos, segundo a classificação da Empresa Brasileira de Pesquisa Agropecuária EMBRAPA (2008), atualizadas a partir dos dados obtidos junto a EMBRAPA (1984).

Segundo o Instituto Agronômico do Paraná (IAPAR, 1994) o clima da área de estudo está enquadrado em dois tipos principais; o primeiro é tropical e abrange o curso inferior e o médio da bacia, e o segundo, subtropical e compreende o curso superior da bacia. $\mathrm{Na}$ porção do baixo Ivaí, os maiores totais médios de temperatura acima de $22{ }^{\circ} \mathrm{C}$ ocorrem em outubro, janeiro e dezembro, enquanto os menores valores, em torno dos $9{ }^{\circ} \mathrm{C}$, acontecem nos meses de agosto, julho e abril. O tipo climático associado ao tipo de cobertura pedológica predominante, favorecem o desenvolvimento de vegetação tipo floresta (Floresta Estacional Semidecidual e Floresta Ombrófila Mista) (CARAMORI, 1989).

\section{METODOLOGIA}

O complexo hidrográfico do Ivaí foi subdivido em 14 (quatorze) sub-bacias de acordo com os pontos de coleta das estações fluviométricas ao longo da bacia do rio Ivaí, de modo que o exutório de cada sub-bacia coincida com a estação de vazão. Houve diferença da área de estudo em relação à área total da bacia (Figura 1), tendo em vista as estações de coleta de vazão, pois a última estação, bem no exutório do rio Ivaí, não apresentou dados coerentes, e por isso teve de ser descartada, reduzindo a área de estudo para $34.419 \mathrm{~km}^{2}$. A quantidade de bacias foi definida para atender a exigência estatística, onde cada bacia corresponderá a um ponto amostral da análise, que no mínimo deve ser 10 (dez) para que a pesquisa apresente resultados satisfatórios. Assim, também a escala de análise não foi a local, mas definida a regional, tendo em vista o tempo e a demanda de trabalho muito extensa ao se trabalhar com diversas bacias hidrográficas ao mesmo tempo.

Para a determinação da morfometria da bacia do rio Ivaí, os seguintes dados foram levantados: ordem de canais, de acordo com o esquema de ordenação de Strahler (1974); número de canais; perímetro total da bacia; altitudes máxima, média e mínima; dimensão do perfil longitudinal total; diferença entre altitudes máxima e mínima da área drenada; 
diferença em metros ao longo do perfil longitudinal; e, área total da bacia. Estes dados foram utilizados para o cálculo de parâmetros morfométricos tais como: densidade hidrográfica; densidade de drenagem; gradiente de canais; relação de relevo; coeficiente de manutenção; índice de circularidade; e, índice de sinuosidade. Os mapas foram gerados em formato digital utilizando-se softwares de Sistemas de Informação Geográficas (SIG's) denominado ArcGis.

Os parâmetros morfométricos referentes à análise linear (CHRISTOFOLETTI, 1980), areal e hipsométrica da rede hidrográfica da bacia do rio Ivaí, foram calculados com as equações específicas apresentadas na Tabela 1.

Tabela 1: Equações utilizadas para o cálculo dos parâmetros morfométricos referentes à análise linear, areal e hipsométrica da rede hidrográfica.

\begin{tabular}{|c|c|c|}
\hline Parâmetro morfométrico & Equação & Variáveis \\
\hline \multicolumn{3}{|l|}{ (a) Análise linear da rede hidrográfica } \\
\hline $\begin{array}{l}\text { Rlm - relação entre os } \\
\text { comprimentos médios dos canais } \\
\text { de cada ordem (adimensional) }\end{array}$ & $R l m=\frac{L m_{w}}{L m_{w-1}}$ & $\begin{array}{l}L m_{w}-\text { comprimento médio dos canais de } \\
\text { determinada ordem }(\mathrm{km}) ; L m_{w-1} \text { - comprimento } \\
\text { médio dos canais de ordem imediatamente } \\
\text { inferior }(\mathrm{km}) \text {. }\end{array}$ \\
\hline $\begin{array}{l}L-\text { comprimento do rio principal } \\
(\mathrm{km})\end{array}$ & $L$ & $\begin{array}{l}\text { Distância da nascente mais distante até a foz } \\
(\mathrm{km})\end{array}$ \\
\hline $\begin{array}{l}\text { Eps - extensão do percurso } \\
\text { superficial }(\mathrm{km})\end{array}$ & $E p s=\frac{1}{2 \cdot D d}$ & $D d$ - densidade de drenagem $\left(\mathrm{km} \mathrm{km}^{-2}\right)$. \\
\hline$G$ - gradiente dos canais $(\%)$ & $G=\left(H-\frac{h}{L}\right) \cdot 100$ & $\begin{array}{l}H-\text { altitude da nascente }(\mathrm{m}) ; h-\text { altitude da foz } \\
(\mathrm{m}) ; L \text { - Comprimento do rio principal }(\mathrm{km}) .\end{array}$ \\
\hline $\begin{array}{l}I_{s i n}-\text { índice de sinuosidade } \\
\text { (adimensional) }\end{array}$ & $I_{\sin }=\frac{L}{L t}$ & $\begin{array}{l}L-\text { comprimento do rio principal }(\mathrm{km}) ; L t- \\
\text { comprimento do eixo da bacia }(\mathrm{km}) .\end{array}$ \\
\hline $\begin{array}{l}L m \text { - comprimento médio dos rios } \\
(\mathrm{km})\end{array}$ & $L m=\frac{L u}{N u}$ & $\begin{array}{l}L u \text { - extensão total dos rios }(\mathrm{km}) ; N u \text { - número } \\
\text { total de rios (quantidade). }\end{array}$ \\
\hline \multicolumn{3}{|l|}{ (b) Análise areal da rede hidrográfica } \\
\hline$A$ - Area da bacia $\left(\mathrm{m}^{2}\right.$ ou km²) & $A$ & $\begin{array}{l}\text { Refere-se à toda área drenada pelo conjunto } \\
\text { do sistema fluvial, fornecida em } \mathrm{m}^{2} \text { ou } \mathrm{km}^{2} \text {, } \\
\text { principalmente. }\end{array}$ \\
\hline $\begin{array}{l}F f \quad-\text { fator forma da bacia } \\
\text { (adimensional) }\end{array}$ & $F f=\frac{A}{L^{2}}$ & $\begin{array}{l}A \text { - área da bacia }\left(\mathrm{km}^{2}\right) ; L \text { - comprimento do } \\
\text { eixo }(\mathrm{km}) .\end{array}$ \\
\hline $\begin{array}{l}K_{c}-\text { índice de compacidade } \\
\text { (adimensional) }\end{array}$ & $K_{c}=\frac{P}{2 \sqrt{\pi \cdot A}}$ & $\begin{array}{l}P \text { - perímetro da bacia }(\mathrm{km}) ; A \text { - área da bacia } \\
\left(\mathrm{km}^{2}\right) .\end{array}$ \\
\hline$D r$ - densidade de rios $\left(\right.$ rios $\mathrm{km}^{-2}$ ) & $D r=\frac{N}{A}$ & $\begin{array}{l}N \text { - número de nascentes (quantidade); } A- \\
\text { área da bacia }\left(\mathrm{km}^{2}\right) .\end{array}$ \\
\hline $\begin{array}{l}D d-\text { densidade de drenagem }(\mathrm{km} \\
\left.\mathrm{km}^{-2}\right)\end{array}$ & $D d=\frac{L t}{A}$ & $\begin{array}{l}L t-\text { comprimento total dos canais }(\mathrm{km}) ; A- \\
\text { área da bacia }\left(\mathrm{km}^{2}\right) .\end{array}$ \\
\hline $\begin{array}{l}C m \text { - coeficiente de manutenção }\left(\mathrm{m}^{2}\right. \\
\left.\mathrm{m}^{-1}\right)\end{array}$ & $C m=\frac{1}{D d} \cdot 1000$ & $D d$ - densidade de drenagem $\left(\mathrm{km} \mathrm{km}^{-2}\right)$. \\
\hline \multicolumn{3}{|c|}{ (c) Análise hipsométrica da rede hidrográfica } \\
\hline $\begin{array}{l}H m-\text { amplitude altimétrica } \\
\text { máxima da bacia }(\mathrm{m})\end{array}$ & $H m=A N-A F$ & $\begin{array}{l}A F-\text { altitude da foz }(\mathrm{m}) ; A N-\text { altitude do } \\
\text { ponto mais alto do divisor topográfico }(\mathrm{m}) \text {. }\end{array}$ \\
\hline
\end{tabular}




\begin{tabular}{|c|c|c|}
\hline$R_{r}-$ relação de relevo $\left(\mathrm{m} \mathrm{m}^{-1}\right)$ & $R r=\frac{H m}{L b}$ & $\begin{array}{l}H m \text { - amplitude topográfica máxima }(\mathrm{m}) ; L b \\
\text { - comprimento da bacia }(\mathrm{m}) \text {. }\end{array}$ \\
\hline $\begin{array}{l}I r-\quad \text { índice de rugosidade } \\
\text { (adimensional) }\end{array}$ & $I r=\mathrm{H} \cdot \mathrm{Dd}$ & $\begin{array}{l}H-\text { amplitude altimétrica }(\mathrm{km}) ; \quad D d- \\
\text { densidade de drenagem }\left(\mathrm{km} \mathrm{km}^{-2}\right) .\end{array}$ \\
\hline $\begin{array}{l}T t \quad-\quad \text { textura topográfica } \\
\text { (adimensional) }\end{array}$ & $T t=\frac{1,6582462}{D d^{1,115}}$ & $D d$ - densidade de drenagem $\left(\mathrm{km} \mathrm{km}^{-2}\right)$. \\
\hline
\end{tabular}

\section{Análise estatística multivariada: Correlação Canônica (ACC)}

O objetivo da correlação canônica é relacionar simultaneamente múltiplas variáveis dependentes e independentes. A correlação canônica mede a força da associação entre dois conjuntos de variáveis. A força do relacionamento entre os pares de variáveis é refletida principalmente pelos coeficientes canônicos de uma primeira função (R canônico). Quando elevados ao quadrado ( $\mathrm{R}^{2}$ canônico), tais coeficientes representam a quantidade de variância em um composto linear da função canônica atribuída a outro composto da mesma função. A análise de correlação canônica tem por objetivo principal verificar a associação entre dois grupos de variáveis, podendo assim, relacionar determinados dados hidrológicos com variáveis que caracterizam o estado físico da bacia hidrográfica. É a técnica que apresentou melhores resultados, uma vez que na análise de agrupamentos e na análise fatorial os resultados não foram positivos.

Para a realização das análises estatísticas multivariadas, foi utilizado o software estatístico BioEstat 5.3 (AYRES et al., 2007), gratuito, desenvolvido no Departamento de Estatística da Universidade Federal do Pará no Brasil.

Nesta pesquisa, para se atender aos objetivos propostos - conhecer e avaliar quais determinantes físicas melhor explicam o comportamento hidrológico nas sub-bacias a fim de validação dos métodos do DFC, foram confrontados os dados de vazões $(X=Q(T P)$; DESVPAD; CV; Q(máx); Q(mín7); Q(mín15); Q(mín30); Q(mín60); Q(mín90)) com as variáveis fisiográficas $(\mathrm{Y}=$ ordem dos canais de drenagem; Lm;Dr;Dd;Eps; Cm;Rr; G; $K c ; I_{s i n} ; I r ; T t ; F f$, de 14 sub-bacias hidrográficas.

\section{RESULTADOS E DISCUSSÃO}

A bacia do rio Ivaí foi subdividida em 14 sub-bacias (Figura 2), as quais equivalem aos 14 pontos amostrais (Tabela 2) utilizados para análise dos dados estatísticos.

Os percentuais se dão em relação à sub-bacia 14, cujo exutório coincide com o último posto de coleta de vazão da área de estudo. As sub-bacias que não recebem contribuição de 
áreas e aportes hidrográficos de sub-bacias à montante, além da 1 são a 5, a 7, a 10 e a 13 (Figura 2).

A sub-bacia 1 compreende as principais nascentes do rio Ivaí, composto pelos rios São João e dos Patos (Tabela 2), com altitudes que variam de $750 \mathrm{~m}$ e $1293 \mathrm{~m}$, tendo como substrato dominante os argilitos, folhelhos e siltitos ritmicamente intercalados com arenitos muito finos, cinza-claros da formação Teresina e Rio do Rasto, respectivamente. O padrão de drenagem retangular e subpararelo obedecem às linhas de falhas, principalmente no sentido NE-SW.

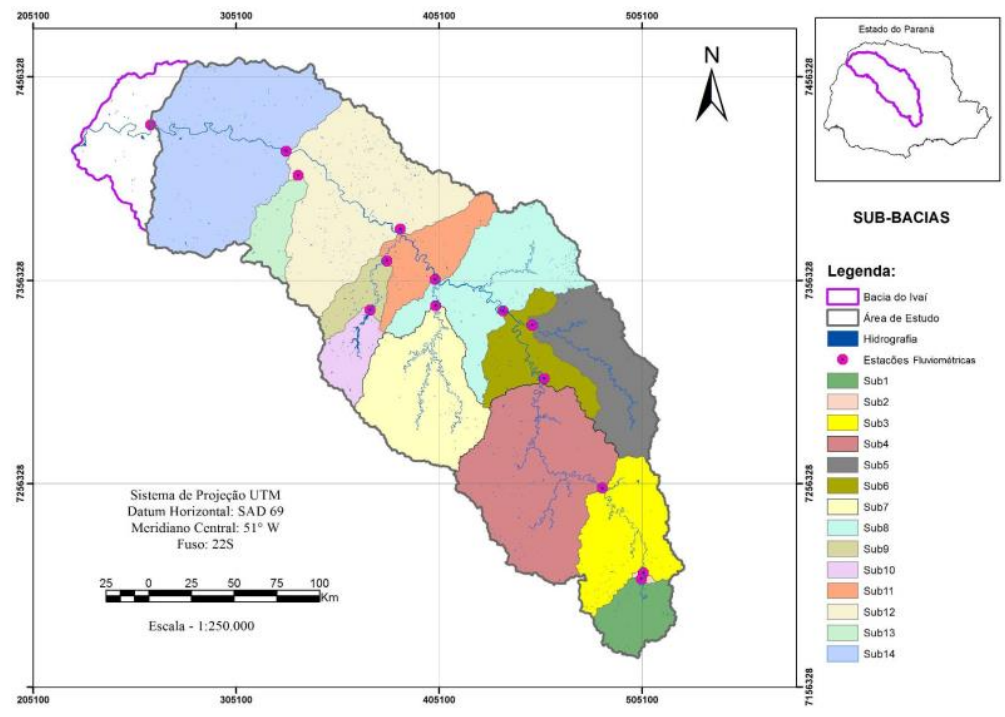

Figura 2: Divisão da bacia do rio Ivaí - PR em 14 sub-bacias.

A sub-bacia 2 compreende basicamente todas as informações da sub-bacia 1 (Figura 2; Tabela 2), com altitudes variando de $742 \mathrm{~m}$ e $1293 \mathrm{~m}$.

A sub-bacia 3 compreende altitudes que variam de $493 \mathrm{~m}$ e $1333 \mathrm{~m}$, tendo como substrato dominante os argilitos, folhelhos da Formação Teresina (Figura 2; Tabela 2). Além do padrão de drenagem retangular e subpararelo observa-se em alguns pontos o padrão dendrítico.

A sub-bacia 4 compreende altitudes que variam de $428 \mathrm{~m}$ e $1333 \mathrm{~m}$, tendo como substrato dominante os argilitos, folhelhos da formação Teresina, os arenitos da formação Botucatu e Rio do Rasto, lavas ácidas e intermediárias da formação Nova Prata (Figura 2; Tabela 2). Além do padrão de drenagem retangular e subpararelo observa-se em alguns pontos o padrão dendrítico e radial.

A sub-bacia 5 compreende altitudes que variam de $403 \mathrm{~m}$ e $1284 \mathrm{~m}$, tendo como substrato dominante alternância de argilitos, folhelhos e siltitos de cor cinza médio 
esverdeada, frequentes níveis de sílex e calcários esbranquiçados da formação Teresina, e os siltitos e argilitos intercalados de arenitos finos, cores esverdeadas, avermelhadas e arroxeadas, níveis ocasionais de calcário e sílex, laminações paralelas, por vezes cruzadas da formação Rio do Rastro (Figura 2; Tabela 2). Além do padrão de drenagem retangular e subpararelo observa-se vertentes curtas.

A sub-bacia 6 compreende altitudes que variam de $362 \mathrm{~m}$ e $1333 \mathrm{~m}$, englobando todas as sub-bacias anteriores com suas informações. 
Tabela 2: Informações fluviométricas da bacia do rio Ivaí por compartimento.

\begin{tabular}{|c|c|c|c|c|c|c|}
\hline Sub-bacia & Código & Estação & Rio & Município & Área $\left(\mathbf{k m}^{2}\right)$ & Instalação \\
\hline 1 & 64619950 & SÃO PEDRO & dos Patos & Prudentópolis & 1054.1 & $11 / 01 / 1983$ \\
\hline 2 & 64620000 & RIO DOS PATOS & dos Patos & Prudentópolis & 1089.6 & $20 / 05 / 1930$ \\
\hline 3 & 64652000 & PORTO MONTEIRO & Alonzo & Grandes Rios & 3566.5 & 01/10/1974 \\
\hline 4 & 64671000 & SALTO NATAL & Mourão & Campo Mourão & 8545.2 & $18 / 02 / 1974$ \\
\hline 5 & 64625000 & TEREZA CRISTINA & Ivaí & Cândido de Abreu & 2611.9 & 08/06/1956 \\
\hline 6 & 64675002 & PORTO BANANEIRAS & Ivaí & Engenheiro Beltrão & 12703.8 & 02/01/1974 \\
\hline 7 & 64645000 & PORTO ESPANHOL & Ivaí & Rio Branco do Ivaí & 3277.1 & $08 / 12 / 1965$ \\
\hline 8 & 64655000 & UBÁ DO SUL & Ivaí & Lidianópolis & 19436.1 & $15 / 04 / 1967$ \\
\hline 9 & 64660500 & VILA RICA & Ivaí & Fênix & 1553.3 & $14 / 08 / 1985$ \\
\hline 10 & 64659000 & BARBOSA FERRAZ & Corumbataí & Barbosa Ferraz & 854.2 & 08/12/1974 \\
\hline 11 & 64673000 & QUINTA DO SOL & Mourão & Quinta do Sol & 22498.5 & 08/08/1974 \\
\hline 12 & 64682000 & JAPURÁ & dos Índios & Japurá & 28403.1 & 08/02/1976 \\
\hline 13 & 64685000 & PORTO PARAISO DO NORTE & Ivaí & Rondon & 802.5 & $23 / 05 / 1952$ \\
\hline 14 & 64693000 & NOVO PORTO TAQUARA & Ivaí & Douradina & 34419.3 & 07/12/1974 \\
\hline
\end{tabular}


A sub-bacia 7 compreende altitudes que variam de $323 \mathrm{~m}$ e $1154 \mathrm{~m}$, tendo como substrato dominante os derrames de basalto da Formação Serra Geral, além de lavas ácidas e intermediárias, da Formação Serra Geral - Membro Nova Prata (Figura 2; Tabela 2). Os derrames vulcânicos são representados por basalto amigdaloidal de base, basalto compacto, basalto amigdaloidal, basalto vesicular e brecha basáltica e/ou sedimentar. Entre dois derrames consecutivos podem ocorrer intercalações de materiais intertrapianos, correspondentes a arenitos e siltitos. O padrão de drenagem que se destaca é o dendrítico com vertentes curtas.

A sub-bacia 8 compreende altitudes que variam de $307 \mathrm{~m}$ e $1333 \mathrm{~m}$, englobando todas as sub-bacias anteriores com suas informações (Figura 2; Tabela 2) com significativo aumento da Formação Serra Geral do grupo São Bento.

As sub-bacias 9 e 10 compreendem altitudes que variam de $311 \mathrm{~m}$ e $849 \mathrm{~m}$, tendo como substrato dominante os derrames de basalto da Formação Serra Geral, já descritos. O padrão de drenagem que se destaca é o dendrítico com vertentes curtas.

A sub-bacia 11 compreende altitudes que variam de $278 \mathrm{~m}$ e $1333 \mathrm{~m}$, englobando todas as sub-bacias anteriores com suas informações, com aumento considerável na Formação Serra Geral, descrita anteriormente.

A sub-bacia 12 compreende altitudes que variam de $255 \mathrm{~m}$ e $1333 \mathrm{~m}$. Neste ponto da bacia já começa a aflorar a Formação Caiuá com os depósitos sedimentares continentais constituídos predominantemente por arenitos médios a finos, quartzosos, com feldspato, calcedônia e opacos, com tendência para apresentar termos mais finos na porção inferior do pacote, e termos mais grossos nas porções superiores. Os arenitos apresentam-se cimentados por pequenas quantidades de hidróxidos de ferro e argila, podendo ocasionalmente apresentar intensa cimentação por sílica, originando variedades duras e resistentes. A maior parte das áreas de ocorrência do Arenito Caiuá apresenta-se coberto por espessura variável (até duas dezenas de metros) de coluviões arenosos a areno-argilosos de idade quaternária. Também a classe geológica dos Sedimentos Inconsolidados passa a ficar bem significativa, por se apresentar próxima a foz do rio principal, o Ivaí. O padrão de drenagem que se destaca é o dendrítico com vertentes médias.

A sub-bacia 13 é composta principalmente pelo rio dos Índios, localizado na margem direita do rio Ivaí (Figura 2) e compreende altitudes que variam de $285 \mathrm{~m}$ e $603 \mathrm{~m}$ fazendo parte da sub-bacia 12, e inteiramente abrangida pela Formação Caiuá, descrita anteriormente. 
A sub-bacia 14 compreende altitudes que variam de $242 \mathrm{~m}$ e $1333 \mathrm{~m}$ e abrange todas as sub-bacias descritas anteriormente (Figura 2).

Os resultados das variáveis morfométricas das sub-bacias hidrográficas da presente pesquisa se resumem da seguinte forma: as sub-bacias 5, 6, 3, 4 e 8 foram as que apresentaram maior rede de drenagem, com Dr igual a 9.47, 5.89, 5.35, 5.27 e 4.37 rios $/ \mathrm{km}^{2}$, respectivamente. As sub-bacias 11, 12, 14, 2 e 1, comparativamente, podem ser consideradas intermediárias em relação a este parâmetro e as sub-bacias 13, 9 e 10 são menores. O padrão de drenagem foi dendrítico endorreico, refletindo, em parte a geologia da região, sendo que, em geral, este padrão é observado na presença de rochas com resistência uniforme.

Quanto maior a somatória do comprimento dos canais de drenagem, maior o número de rios e declividade do terreno. Quanto maior a declividade do terreno, maior a incidência à tendência de processos erosivos, maior o deflúvio superficial e menor a permeabilidade dos solos de textura fina. A densidade de drenagem tende a zero nas zonas áridas, de topografia plana e solos arenosos e a máxima nas áreas úmidas, montanhosas e de terrenos impermeáveis (BARBOSA; CARVALHO, 2009).

No geral das sub-bacias, a densidade de drenagem foi considerada alta (acima de 2.0 $\mathrm{km} / \mathrm{km}^{2}$ ), sendo que apenas 4 das 14 apresentaram Dd entre 0.85 e 1.86 (sub-bacias 13, 10, 7 e 9). Este resultado é coerente com os solos das nascentes da bacia (Cambissolo e Neossolos), que apresentam maior impermeabilidade em relação aos demais solos da área estudada, principalmente pela associação à alta declividade, dominando assim o escoamento superficial em relação à infiltração. Já os solos arenosos, que associados à baixa declividade, são mais permeáveis e com isso apresentam densidade de drenagem menor, são as áreas mais próximas à foz da bacia do rio Ivaí.

\section{Correlação Canônica aplicada ao levantamento morfométrico em canais fluviais}

Assim, o grupo das variáveis dependentes são 09: vazão média de longo período; vazão máxima - Q(máx), as vazões mínimas (de 7, 15, 30, 60 e 90 dias), o desvio padrão (DESVPAD) e o coeficiente de variação (CV), do período médio de 1985 a 2012 (Tabela $3)$.

Para o levantamento morfométrico em canais fluviais o resultado da correlação canônica (Tabela 4) mostrou para todos os índices do método que os mesmos não são 
independentes em relação à vazão e, portanto a validação do método ocorre. A média geral das variáveis mostra resultado bem significativo com $R$ canônico igual a 0.961 e com $R^{2}$ canônico igual a 0.925, qui-quadrado com 9 GL (graus de liberdade) igual a 27.496 e pvalor $=0.036$, ou seja, probabilidade de erro estatístico baixo, não atinge 5\% (Tabela 4).

Tabela 3: Parâmetros hidrológicos por sub-bacia - rio Ivaí PR.

\begin{tabular}{ccccc|ccccc}
\hline $\begin{array}{c}\text { Sub- } \\
\text { bacia }\end{array}$ & $\begin{array}{c}\text { Q } \\
\text { (média) }\end{array}$ & $\begin{array}{c}\text { DESV } \\
\text { PAD }\end{array}$ & CV & (máx) & \multicolumn{5}{c}{ Q (mín - dias) } \\
\hline & & & & & 7 & 15 & 30 & 60 & 90 \\
\hline 1 & 27.7 & 26.88 & 0.970 & 291.7 & 3.6 & 4.1 & 5.0 & 6.7 & 9.3 \\
2 & 26.6 & 24.89 & 0.935 & 286.5 & 3.7 & 4.2 & 5.1 & 6.6 & 9.3 \\
3 & 23.1 & 21.70 & 0.941 & 332.0 & 2.9 & 3.3 & 4.1 & 5.5 & 9.1 \\
4 & 24.4 & 20.39 & 0.834 & 245.3 & 3.9 & 4.6 & 5.4 & 6.8 & 9.0 \\
5 & 20.9 & 18.83 & 0.903 & 335.8 & 2.4 & 2.7 & 3.3 & 4.5 & 6.7 \\
6 & 22.5 & 18.62 & 0.826 & 244.9 & 3.9 & 4.4 & 5.1 & 6.4 & 8.5 \\
7 & 23.4 & 22.46 & 0.959 & 447.4 & 1.8 & 2.1 & 2.7 & 3.9 & 6.4 \\
8 & 23.4 & 19.93 & 0.851 & 272.0 & 3.7 & 4.1 & 4.8 & 6.3 & 8.4 \\
9 & 22.0 & 9.70 & 0.440 & 149.1 & 8.7 & 9.8 & 10.9 & 12.3 & 13.3 \\
10 & 23.1 & 10.06 & 0.436 & 89.0 & 8.2 & 9.6 & 11.2 & 13.2 & 14.6 \\
11 & 22.6 & 16.82 & 0.743 & 206.8 & 5.1 & 5.5 & 6.2 & 7.6 & 9.6 \\
12 & 20.2 & 14.13 & 0.700 & 152.6 & 5.6 & 6.0 & 6.6 & 7.8 & 9.5 \\
13 & 17.4 & 5.41 & 0.311 & 76.3 & 10.8 & 11.3 & 11.8 & 12.7 & 13.3 \\
14 & 19.6 & 12.53 & 0.638 & 107.5 & 6.7 & 7.0 & 7.6 & 8.7 & 10.1 \\
\hline
\end{tabular}

Legenda: Q = Vazão $\left(1 / \mathrm{s} / \mathrm{km}^{2}\right) ;$ DESVPAD = Desvio Padrão; CV = Coeficiente de Variação; Q(máx) $=$ Vazões Máximas Anuais (valores médios); Q(mín) = Vazões mínimas (valores médios).

Índices morfométricos que apresentaram maior correlação com a vazão, com $\mathrm{R}$ canônico acima de 0.98 , na sequência foram: $R p b$ (a relação ponderada de bifurcação - onde rios de duas ordens são relacionados); Rlmp (Relação dos comprimentos médios dos canais ponderada); $T t$ (Textura topográfica - relaciona a densidade de drenagem a valores constantes); Eps (Extensão do percurso superficial - também relaciona a densidade de drenagem); $C m$ (Coeficiente de manutenção - relaciona a densidade de drenagem); Or (Ordem dos canais); Lm (o comprimento médio dos rios), todos com p-valor altamente significativo ( $\mathrm{p}<0.0001)$ (Tabela 4).

Os índices Eps e Cm apresentaram resultados canônicos muito próximos (Tabela 4), o que era de se esperar, tendo em vista a se utilizaram da $D d$ em seu levantamento. Entretanto cada um deles apresentam interpretações e explicações para situações distintas e os mesmos não devem ser substituídos uns pelos outros. O que se deve ter em mente é a validação destes índices, que foram confirmadas. A $R p b$, a $T t$, a $E p s$ e o $C m$ são explicados principalmente pelo desvio padrão das vazões médias de longo período, pelo coeficiente de variação, pelas vazões máximas diárias e também pelas mínimas de 7, 15, 30, 60 e 90 dias. 
A $R \operatorname{lmp}$ e a $L m$ são explicadas pelo desvio padrão, coeficiente de variação das vazões, bem como pelas vazões mínimas de 7, 15, 30, 60 e 90 dias. A ordem dos canais fluviais é explicada pelo coeficiente de variação das vazões, bem como pelas vazões mínimas de 7, $15,30,60$ e 90 dias.

Tabela 4: Correlações canônicas: morfometria relacionada à vazão de rios - bacia do rio Ivaí.

\begin{tabular}{|c|c|c|c|c|c|}
\hline & R canônico & R2 canônico & Qui-quadrado & GL & p-valor \\
\hline$R p b$ & 0.998 & 0.995 & 45.643 & 9 & 0.000 \\
\hline Rlmp & 0.997 & 0.995 & 44.400 & 9 & 0.000 \\
\hline$T t$ & 0.994 & 0.987 & 37.035 & 9 & 0.000 \\
\hline Eps & 0.992 & 0.985 & 35.655 & 9 & 0.000 \\
\hline $\mathrm{Cm}$ & 0.992 & 0.985 & 35.464 & 9 & 0.000 \\
\hline Or & 0.992 & 0.983 & 34.773 & 9 & 0.000 \\
\hline$L m$ & 0.989 & 0.979 & 32.904 & 9 & 0.000 \\
\hline $\mathrm{Hm}$ & 0.983 & 0.967 & 28.959 & 9 & 0.001 \\
\hline$R r$ & 0.974 & 0.949 & 25.227 & 9 & 0.003 \\
\hline$I r$ & 0.964 & 0.930 & 22.601 & 9 & 0.007 \\
\hline$K c$ & 0.955 & 0.913 & 20.754 & 9 & 0.014 \\
\hline$G$ & 0.951 & 0.905 & 20.023 & 9 & 0.018 \\
\hline$D d$ & 0.920 & 0.847 & 15.969 & 9 & 0.068 \\
\hline$I \sin$ & 0.920 & 0.847 & 15.964 & 9 & 0.068 \\
\hline$D r$ & 0.874 & 0.764 & 12.277 & 9 & 0.198 \\
\hline$F f$ & 0.874 & 0.764 & 12.289 & 9 & 0.198 \\
\hline Média & 0.961 & 0.925 & 27.496 & 9 & 0.036 \\
\hline
\end{tabular}

Em seguida o Hm (amplitude altimétrica máxima) que apresenta alto R canônico, igual a 0.983 , com $\mathrm{R}^{2}$ canônico igual a 0.967 , qui-quadrado com 9 GL igual a 28.959 e p-valor igual a 0.001. O Hm é explicado principalmente pelas vazões mínimas de 15, 30, 60 e 90 dias. Em seguida aparece o índice $R r$ (relação de relevo entre a amplitude altimétrica máxima e o comprimento da bacia), com $\mathrm{R}$ canônico igual a 0.974 e com $\mathrm{R}^{2}$ canônico igual a 0.949 , qui-quadrado com 9 GL (graus de liberdade) igual a 25.227 e $p$-valor significativo (p 0.003), ou seja, probabilidade de erro estatístico muito baixo. Este índice obteve boa resposta em relação aos resultados médios de longo período, desvio padrão e as máximas das vazões no período analisado.

O Índice de Rugosidade (Ir) apresenta R canônico igual a 0.964 e com $\mathrm{R}^{2}$ canônico igual a 0.930, qui-quadrado com 9 GL (graus de liberdade) igual a 22.601 e p-valor significativo $(\mathrm{p}=0.007)$. As maiores correlações foram obtidas pelo coeficiente de variação e vazões mínimas. 
O Índice de Compacidade $(K c)$ apresentou $\mathrm{R}$ canônico igual a 0.955 e com $\mathrm{R}^{2}$ canônico igual a 0.913, qui-quadrado com 9 GL (graus de liberdade) igual a 20.754 e p-valor significativo $(\mathrm{p}=0.014)$. A correlação maior ocorre com a vazão média de longo prazo.

$\mathrm{O}$ índice $G$ (gradiente dos canais) com $\mathrm{R}$ canônico igual a 0.951 e com $\mathrm{R}^{2}$ canônico igual a 0.905, qui-quadrado com 9 GL (graus de liberdade) igual a 20.023 e p-valor significativo $(\mathrm{p}=0.018)$. Estes resultados confirmam a eficiência deste parâmetro que relaciona diferença das altitudes com o comprimento do rio principal, validado principalmente pela vazão média de longo prazo.

Os demais índices como $D d$, Isin, $D r$ e $F f$ apresentaram correlações com a vazão com probabilidade de erro maior que 5\%, indicados pelo $p$-valor e, portanto, sua eficiência fica comprometida. $\mathrm{O}$ primeiro e os dois últimos relacionam a área de cada sub-bacia com outras medições, como comprimento de todos os canais pluviais, quantidade de nascentes e comprimento do eixo. Já o Isin relaciona o comprimento do rio principal com o eixo. Entretanto, o parâmetro $D d$ é muito eficiente quando associada a outros parâmetros formando novos índices, como os já mencionados Tt, Cm e Eps.

\section{CONCLUSÃO}

Pelo exposto, fica evidente que a estatística multivariada constitui boa ferramenta para tornar conhecidas variáveis de maior peso no comportamento hidrológico de um sistema hidrográfico, pois permitiu atingir os objetivos propostos na presente pesquisa.

As variáveis do método de levantamento morfométrico em canais fluviais que apresentaram maior resposta no comportamento hidrológico, na sequencia foram a $R p b$, a $R l m p$, a $T t$, a Eps, o Cm, a $O r$ e o $L m$. Também apresentaram bom grau de significância a $H m$, a $R r$, o $I r$, o $K c$ e o $G$. Os índices $D d$, Isin, $D r$ e $F f$ apresentaram boa correlação canônica, entretanto com percentual de erro maior, entre $6.75 \%$ e $19.75 \%$, o que torna o grau de eficiência destes índices reduzida. No geral o método apresentou percentual de erro igual a 0.036 , abaixo dos $5 \%$, o que o torna muito significativo.

Com isso, este método de análise em canais fluviais foi validado com a aplicação da estatística multivariada, na escala regional, tornando este método inquestionável em refletir a realidade em estudos da paisagem e seus processos. As análises de correlação canônica permitiram observar que os grupos não são independentes, isto é, os grupos representados pelo método e os tipos de vazão (vazão média em longo prazo, desvio padrão, coeficiente 
de variação, máximas e mínimas), estão fortemente correlacionados. Estes resultados demonstram também que a atribuição de pesos numéricos ou faixas de critérios para interpretações e generalizações sobre áreas estudadas não invalida o método.

\section{REFERÊNCIAS BIBLIOGRÁFICAS}

ANTONELI, V.; THOMAZ, E. L. Caracterização do meio físico da bacia do Arroio Boa Vista - Guamiranga-PR. Revista on line Caminhos da Geografia, v. 8, n. 21, 46-58, 2007.

AYRES, M., AYRES JR., M., AYRES, D. L., SANTOS, A. S. BioEstat. Versão 5.3, Sociedade Civil Mamirauá, MCT - CNPq, Belém, Pará, Brasil. 2007.

BALDO, M.C. Variabilidade pluviométrica e a dinâmica atmosférica na bacia hidrográfica do rio Ivaí - PR. Presidente Prudente, 2006. 172p. Tese (Doutorado em Geografia), Universidade Estadual Paulista.

BARBOSA, Y.; CARVALHO, S. Análise morfométrica da bacia do arroio do Padre, Ponta Grossa - PR. Caminhos de Geografia. Uberlândia v. 10, n. 29 Mar/2009 p. 160-173.

CARAMORI, P. H. Caracterização Climática. In: Instituto Agronômico do Paraná. Potencial de Uso agrícola das áreas de várzea do Estado do Paraná: bacia hidrográfica do baixo Ivaí. Boletim Técnico. Londrina, n.24, v.1, p.65-69, 1989.

CHRISTOFOLETTI, A. Geomorfologia. $2^{\text {a }}$ Ed. São Paulo: Edgard Blucher, 1980, 188 p. EMBRAPA. Centro Nacional de Pesquisa de Solos. Sistema brasileiro de classificação de solos. Rio de Janeiro: Embrapa Solos, 2008.

EMBRAPA. Empresa Brasileira de Pesquisa Agropecuária. Serviço nacional de levantamento e conservação de solos. Levantamento de reconhecimento dos solos do estado do Paraná. Londrina: IAPAR. Dois tomos, 1984.

IAPAR - INSTITUTO AGRONÔMICO DO ESTADO DO PARANÁ. Cartas climáticas do Estado do Paraná. Londrina, IAPAR, 1994. 49 p. ( Documento, 18).

MAACK, R. Geografia Física do Estado do Paraná. $2^{\circ}$ edição. Rio de Janeiro: Livraria José Olympio Editora, 1981.

SOARES, M.; Souza, J. Análise morfométrica da bacia do rio Pequeno em São José dos Pinhais - PR. Geografia (Londrina), v. 21, p. 019-036, 2012.

STRAHLER, A. Geografia Física. Barcelona: Omega, 1974, 550p.

Recebido em 19 de agosto de 2014.

Aceito em 29 de abril de 2018. 